\title{
Bovine Serum Albumin as a Lyoprotectant for Preparation of DNA Dry Powder Formulations Using the Spray-Freeze Drying Method
}

\author{
Masashi Tsukamoto, ${ }^{a}$ Tomoyuki Okuda,${ }^{b}$ Hirokazu Okamoto, ${ }^{b}$ Yuriko Higuchi, ${ }^{a}$ \\ Shigeru Kawakami, ${ }^{a}$ Fumiyoshi Yamashita, ${ }^{a}$ and Mitsuru Hashida* ${ }^{*, a}$ \\ ${ }^{a}$ Department of Drug Delivery Research, Graduate School of Pharmaceutical Sciences, Kyoto University; Sakyo-ku, \\ Kyoto 606-8501, Japan: ${ }^{b}$ Faculty of Pharmacy, Meijo University; 150 Yagotoyama, Tempaku-ku, Nagoya 468-8503, \\ Japan: and ${ }^{c}$ Institute for Integrated Cell-Material Sciences, Kyoto University; Kyoto 606-8302, Japan. \\ Received December 15, 2011; accepted February 15, 2012; published online April 12, 2012
}

The development of efficient and selective therapeutic gene delivery methods is a potential medical treatment for intractable diseases. Dry powder inhalers (DPIs) can efficiently deliver drugs locally to the lung. Many reports discuss preparation methods for DPIs. Spray-freeze drying is a method by which highly porous particulates can be prepared. However, altered physical properties after preparation may result in changes in gene expression. In this study, bovine serum albumin (BSA) was added as a lyoprotectant, and 1,2-dioleoyl-3-trimethylammonium propane/cholesterol liposomes/pCMV-Luc DPIs (lipoplex DPIs) were prepared by spray-freeze drying. The mean particle sizes of the lipoplex DPIs prepared without BSA increased by approximately 6.7-fold compared with that of the lipoplexes solution. In contrast, the mean particle sizes of the lipoplex/BSA DPIs increased only slightly. Gene expression was evaluated after the intratracheal administration of the lipoplexes solution, with maximum gene expression observed at $12 \mathrm{~h}$ after the administration. In contrast, maximum gene expression of the lipoplex/BSA DPIs occurred at $6 \mathrm{~h}$ after administration. The gene expression associated with the lipoplex DPIs was significantly lower compared with that of the lipoplex/BSA DPIs at $6(p<0.01), 12(p<0.01)$, and $24 \mathrm{~h}(p<0.05)$. These variances may be due to the difference in mean particle size between the DPI formulations. The results suggest that BSA is a useful lyoprotectant for dry powder formulation preparations of DNA using the spray-freeze drying method, given that the preparation results in minimal variation of physical properties and gene expression.

Key words dry powder inhaler; spray-freeze drying; lyoprotectant; bovine serum albumin; pulmonary gene delivery; lipoplex

Gene therapy is expected to be a cure for intractable diseases. However, efficient and selective delivery of therapeutic genes to the target cells is necessary for gene therapy to be effective. ${ }^{1)}$ Although viral vectors may show high gene expression, toxicity as a result of immunogenicity is a major problem associated with their use. Therefore, non-viral vectors have received attention because of their relatively low toxicity. ${ }^{2)}$ Many researchers have demonstrated that cationic liposomes show high gene expression and low toxicity. ${ }^{3-5)}$ Lung diseases such as lung cancer and cystic fibrosis are intractable, and therefore, the realization of efficient gene therapy to treat such conditions is essential. However, the development of delivery methods that enable the local delivery of therapeutic genes to the lung is needed.

The aerosolization of gene vectors is an efficient delivery method, and many related studies have been carried out., ${ }^{6,7}$ However, it is necessary for aerosols to be sprayed immediately because the stability of gene vectors in aqueous solution is low. ${ }^{8)}$ Alternatively, dry powder inhalers (DPIs) are widely used and accepted as an effective system for pulmonary drug delivery. DPIs have many advantages, including increased shelf life of drugs including plasmid DNA (pDNA) and the non-use of a propellant. ${ }^{9,10)}$ Dry powders with an aerodynamic diameter of 1 to $5 \mu \mathrm{m}$ can reach pulmonary alveoli. However, such dry powders are characterized by high adhesion coherence, and therefore, their handling is difficult. ${ }^{11,12)}$

To date, many reports describing methods for the preparation of dry powders, such as lyophilization ${ }^{13,14)}$ and spray drying, ${ }^{15-17)}$ have been published. Among them, freeze-drying is a simple method. In many cases, grinding to fine dry powders is required after freeze-drying. Altered physical properties as a result of grinding may result in changes in gene expression. On the other hand, during preparation by spray drying, physical stress such as heating and spraying results in reduced gene expression. ${ }^{18)}$ The spray-freeze drying method involves spraying components in a cryogen, such as liquid nitrogen; transferring the frozen drops to a freeze dryer; and freeze drying. Highly porous dry powders can be obtained by this method. ${ }^{19,20)}$

However, with the spray-freeze drying method, gene expression may be decreased due to the increase in particle size of the gene vectors during the process of freeze-drying. Many studies report that it is possible to maintain physical properties during freeze-drying. For example, Rudolph et al. ${ }^{14)}$ prepared dry polyethyleneimine/pDNA powders (PEI/pDNA DPIs) by adding disaccharide to maintain the particle size of PEI/ pDNA DPIs. Similar research was reported by Birchall and colleagues $^{17)}$ who prepared dry 2-dioleoyl-3-trimethylammonium propane (DOTAP)/protamine/pDNA powders by adding lactose. While disaccharide is an effective lyoprotectant, a high concentration is needed to maintain the physical properties. $^{21-23)}$

We preliminary investigated the preparation of DPIs by spray-freeze drying using disaccharide (lactose, trehalose, or sucrose) as the main component. Disaccharide DPI formulations absorbed moisture immediately after freeze-drying. However, a disaccharide to pDNA ratio of more than 500 was needed to maintain the particle size. In addition, it also revealed that dextran sodium sulfate that is a negatively charged macromolecule was an effective lyoprotectant to maintain the 
particle size. However, the gene expression was not observed after intratracheal administration of this formulation presumably due to a negatively charged nature $(-33.4 \mathrm{mV})$. Therefore, we selected bovine serum albumin (BSA) as a lyoprotectant. Since BSA is immunogenic, human serum albumin should be selected for practical use. In this study, we prepared DOTAP/ cholesterol liposomes/pDNA complex DPIs (lipoplex/BSA DPIs) by spray-freeze drying. The mean particle size of the lipoplex/BSA DPIs was measured, and the transfection efficacy of lipoplexes/BSA DPIs was evaluated.

\section{MATERIALS AND METHODS}

Materials DOTAP was obtained from Avanti Polar Lipids, Inc. (Alabaster, AL, U.S.A.). Cholesterol and sodium heparin were obtained from Nacalai Tesque Inc. (Kyoto, Japan). BSA, indocyanine green (ICG), and DL-leucine were obtained from Sigma-Aldrich, Co. (St. Louis, MO, U.S.A.). DMannitol was obtained from Wako Pure Chemical Industries, Ltd. (Osaka, Japan). $\lambda$ HindIII was obtained from Takara Bio Inc. (Shiga, Japan).

Plasmid cytomegalovirus (pCMV)-Luc was constructed by subcloning the HindIII/XbaI firefly luciferase cDNA fragment from the pGL3-control vector (Promega Co., Madison, WI, U.S.A.) into the polylinker of pcDNA3 vector (Invitrogen, Carlsbad, CA, U.S.A.). pCMV-Luc was amplified in the DH5 $\alpha$ Escherichia coli strain, isolated, and purified using QIAGEN Endofree Plasmid Giga Kit (QIAGEN GmbH, Hilden, Germany). The concentration of pCMV-Luc was determined by measuring UV absorption at $260 \mathrm{~nm}$. All other chemicals used were of the highest purity available.

Preparation of the DOTAP/Cholesterol Liposomes DOTAP/cholesterol liposomes were prepared according to the method reported previously. ${ }^{24)}$ In brief, DOTAP and cholesterol were dissolved in chloroform at a molar ratio of $1: 1$. The mixture was vacuum-desiccated and resuspended in sterile water. After hydration for $30 \mathrm{~min}$, the suspension was sonicated in a tip-type sonicator on ice for $8 \mathrm{~min}$.

Preparation of the Lipoplexes Lipoplexes were prepared according to the method reported previously. ${ }^{25,26)}$ In brief, an equal volume of pCMV-Luc in sterile water was added to the liposomes at a mixing ratio $(+/-)$ of $3: 1$ and left at room temperature for $30 \mathrm{~min}$.

Preparation of Dry Powders by Spray-Freeze Drying Each formulation is listed in Table 1. For the preparation of dry powders, the additional agent was added into the lipoplexes solution. The mixture was sprayed into liquid nitrogen using an intratracheal aerosolizer (1A-1C, PennCentury, Inc., Wyndmoor, PA, U.S.A.). After spraying, the liquid nitrogen including the droplets was transferred to a freeze dryer (FDU-2200, Tokyo Rikakikai Co., Ltd., Tokyo, Japan).

Particle Size and Zeta Potential The particle size and zeta potential were measured using a Zetasizer Nano ZS instrument (Malvern Instruments, Ltd., Worcestershire, U.K.). The final concentration of pCMV-Luc was $10 \mu \mathrm{g} / \mathrm{mL}$.

Electrophoresis The dry powders were dissolved in sterile water. Then, $15 \mu \mathrm{L}$ of the lipoplex DPIs and lipoplex/BSA DPIs $(3 \mathrm{mg} / \mathrm{mL})$ were each mixed with $15 \mu \mathrm{L}$ of sodium heparin $(1.33 \mathrm{mg} / \mathrm{mL})$ to peel pCMV-Luc from the lipoplex DPIs. After mixing with the loading buffer, each sample containing $0.1 \mu \mathrm{g}$ of pCMV-Luc was added to the wells of a $1.0 \%$ agarose gel. Electrophoresis was carried out at a current of $100 \mathrm{~V}$ and a voltage of $150 \mathrm{~mA}$ for $30 \mathrm{~min}$ in TAE running buffer. A $\lambda$ HindIII DNA ladder was used as a size marker.

In Vivo Pulmonary Transfection Five-week-old female ICR mice (22-24g) were purchased from Japan SLC (Shizuoka, Japan). All animal experiments were carried out in accordance with the Principles of Laboratory Animal Care as adopted and promulgated by the U.S. National Institutes of Health and the Guidelines for Animal Experiments of Kyoto University.

Mice were anesthetized with pentobarbital $(50 \mathrm{mg} / \mathrm{kg}$, intraperitoneally (i.p.)), and a board was secured on their backs during experiments. Their tracheas were exposed, and $2.5 \mathrm{~cm}$ of PE-60 polyethylene tubing (internal diameter, $0.76 \mathrm{~cm}$; Becton, Dickinson and Company, Franklin Lakes, NJ, U.S.A.) was inserted to a depth of $1.0 \mathrm{~cm}$ through an incision. The dry powders were administered through the trachea using an appropriate apparatus for mice. $\left.{ }^{27}\right)$ The dry powders $(1.5 \mathrm{mg})$ were placed in a disposable tip and dispersed in the trachea by releasing air $(0.35 \mathrm{~mL})$ compressed in a syringe by opening a three-way stopcock that connects the disposable tip and the syringe. At $15 \mathrm{~min}$ after administration, ICG fluorescence was determined using an in vivo imaging system (Night OWL LB981, Bethold Technology, Germany). We evaluated gene expression in mice that exhibited significant fluorescence in their lungs. For the intratracheal administration of the solution, $50 \mu \mathrm{L}$ of the solution containing $10 \mu \mathrm{g}$ of pCMV-Luc with $101.9 \mu \mathrm{g}$ DOTAP $(65.6 \mu \mathrm{g})$ and cholesterol $(36.3 \mu \mathrm{g})$ liposomes was administered into the mice tracheas by the aerosolizer. The mice were sacrificed at 6,12 , and $24 \mathrm{~h}$ after the administration. Their lungs were harvested, and homogenates were prepared by adding lysis buffer $(4 \mu \mathrm{L} / \mathrm{mg})$. The homogenates were subjected to 3 cycles of freezing and thawing, and centrifuged at $10000 \times \boldsymbol{g}$ for $10 \mathrm{~min}$ at $4^{\circ} \mathrm{C}$. Subsequently, $20 \mu \mathrm{L}$ of the supernatant was analyzed for luciferase activity with $100 \mu \mathrm{L}$ of luciferase assay buffer (Picagene, Toyo Ink, Co., Tokyo, Japan) using a luminometer (Lumat LB 9507, EG\&G Berthhold, Bad, Wildbad, Germany). The protein content in the supernatants was determined using a protein quantification kit (Dojindo Molecular Technologies, Inc., Kumamoto, Japan).

Statistical Analysis Statistical analysis was performed using the Student's paired $t$-test for 2 groups. A $p<0.05$ was considered to be statistically significant.

Table 1. Formulation of DPIs (Dose/Mice)

\begin{tabular}{lccccccc}
\hline \hline & \multicolumn{7}{c}{ Formulation composition $(\mu \mathrm{g})$} \\
\cline { 2 - 7 } & pCMV-Luc & DOTAP & Cholesterol & ICG & Leucine & BSA & Mannitol \\
\hline Lipoplexes & 10 & 65.6 & 36.3 & 10 & 300 & 0 & 1078.1 \\
Lipoplexes/BSA & 10 & 65.6 & 36.3 & 10 & 300 & 305.7 & 772.4 \\
\hline
\end{tabular}


Table 2. Particle Size, Zeta Potential and Polydispersity Index of DOTAP/Cholesterol Liposomes, Lipoplex Solutions and DPI Formulations

\begin{tabular}{lccc}
\hline \hline & Particle size $(\mathrm{nm})$ & $\begin{array}{c}\text { Zeta potential } \\
(\mathrm{mV})\end{array}$ & $\begin{array}{c}\text { Polydispersity } \\
\text { index }\end{array}$ \\
\hline $\begin{array}{c}\text { DOTAP/choles- } \\
\text { terol lipo- } \\
\text { somes }\end{array}$ & $92.6 \pm 1.16$ & $71.1 \pm 3.04$ & $0.225 \pm 0.01$ \\
$\begin{array}{c}\text { Lipoplexes } \\
\text { solutions }\end{array}$ & $151 \pm 0.58$ & $49.8 \pm 0.90$ & $0.228 \pm 0.01$ \\
$\begin{array}{l}\text { Lipoplex DPIs } \\
\text { Lipoplex/BSA } \\
\text { DPIs }\end{array}$ & $1005 \pm 59.6$ & $48.9 \pm 1.85$ & $0.726 \pm 0.02$ \\
\hline
\end{tabular}

Each value represents the mean \pm S.D. for 3 measurements.

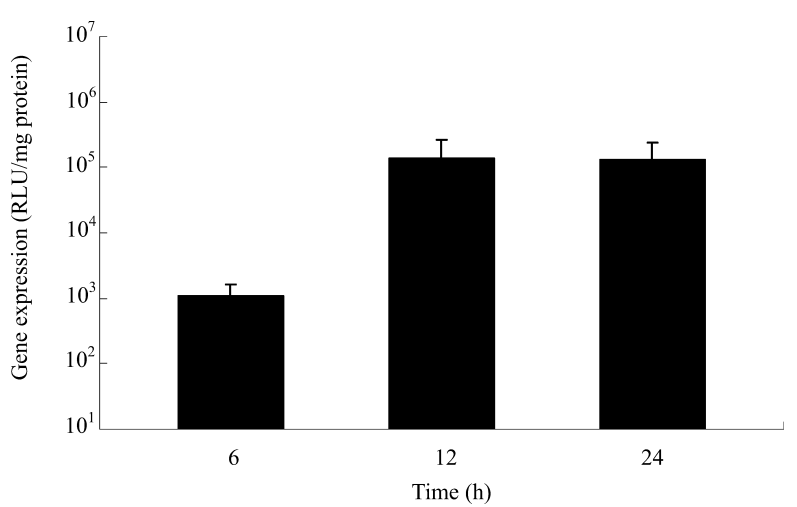

Fig. 1. Pulmonary Transfection Efficiency after Intratracheal Administration of the Lipoplex Solution

Each value represents the mean \pm S.D. for at least 4 mice.

\section{RESULTS AND DISCUSSION}

Table 1 summarizes the formulation of each DPI studied. Similar to a previous report by Okamoto and colleagues ${ }^{20,28)}$ ICG was also encapsulated in the DPI formulation to confirm delivery into the lung. Particle size and zeta potential were measured to evaluate the physicochemical properties of the DPI formulations. Table 2 shows the physicochemical properties of each DPI formulation. The mean particle size of the lipoplexes solution was $151 \pm 0.58 \mathrm{~nm}$. The mean particle sizes of the lipoplex DPIs and the lipoplex/BSA DPIs were 1005士 59.6 and $171 \pm 1.0 \mathrm{~nm}$, respectively. The particle size of the lipoplex DPIs was approximately 6.7-fold higher than that of the fresh lipoplexes solution, while the mean particle size of the lipoplex/BSA DPIs was increased only slightly. The zeta potential of the lipoplexes solution was $49.8 \pm 0.90 \mathrm{mV}$, while that of the lipoplex DPIs and the lipoplex/BSA DPIs was $48.9 \pm 1.85$ and $31.8 \pm 0.76 \mathrm{mV}$, respectively. The zeta potential of the dry lipoplex/BSA DPIs was decreased compared with that of the fresh lipoplexes solution. No significant difference between the zeta potential of the lipoplex DPIs and that of the lipoplexes solution was observed.

The solution containing $10 \mu \mathrm{g}$ pCMV-Luc and $101.9 \mu \mathrm{g}$ DOTAP $(65.6 \mu \mathrm{g})$ and cholesterol $(36.3 \mu \mathrm{g})$ liposomes was administered intratracheally, and gene expression at 6,12 , and $24 \mathrm{~h}$ after administration was evaluated. Figure 1 shows the pulmonary transfection efficiency of intratracheal administration in mice. Maximum gene expression was observed $12 \mathrm{~h}$ after administration, and was almost maintained $24 \mathrm{~h}$ after

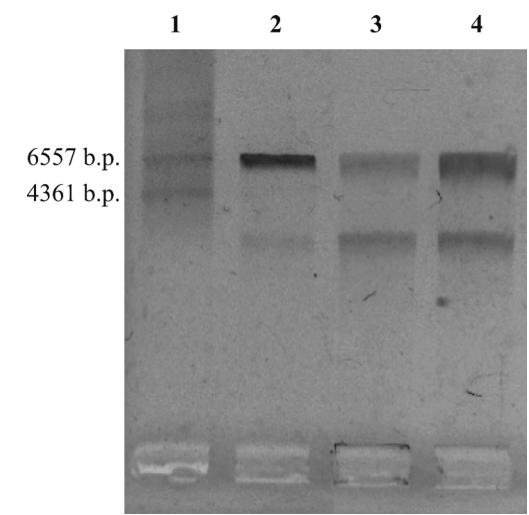

Fig. 2. Electrophoresis of the DPI Formulations. $15 \mu \mathrm{L}$ of the Lipoplex DPIs and of the Lipoplex/BSA DPIs $(3 \mathrm{mg} / \mathrm{mL})$ Were Mixed with $15 \mu \mathrm{L}$ of Sodium Heparin $(1.33 \mathrm{mg} / \mathrm{mL})$ to Peel pCMV-Luc from the Lipoplex DPIs

Lane 1: size marker; lane 2: pCMV-Luc solution; lane 3: lipoplex DPIs; lane 4 lipoplex/BSA DPIs

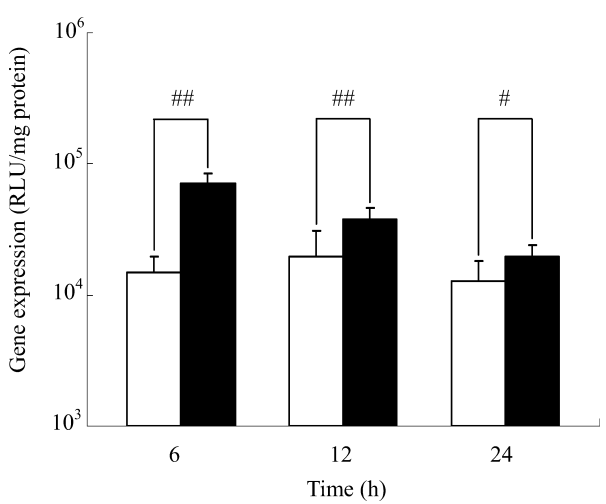

Fig. 3. Pulmonary Transfection Efficiency after Intratracheal Administration of the DPI Formulations

Gene expression of the lipoplex DPIs is represented by $\square$, while gene expression of the lipoplex/BSA DPIs is represented by $\mathbf{\square}$. Each value represents the mean \pm S.D. for at least 4 mice. Statistical analysis was performed using the Student's $t$-test $\left({ }^{\#} p<0.05,{ }^{\#} p<0.01\right)$.

administration.

To evaluate the stability of pCMV-Luc during the preparation by spray-freeze drying, electrophoresis was carried out (Fig. 2). Each lipoplex DPI and lipoplex/BSA DPI was mixed with heparin to peel pCMV-Luc from the lipoplex DPIs. Naked pCMV-Luc solution was selected as the control. A DNA ladder was not observed for either of the DPIs, suggesting that degradation during preparation by spray-freeze drying is negligible. In the presence of BSA, the band associated with supercoiled DNA (about $6500 \mathrm{bp}$ ) was relatively retained, indicating that stabilization was improved.

Gene expression characteristics were evaluated after the pulmonary administration of each dry powder formulation. As shown in Fig. 3, maximum gene expression of the lipoplex/BSA DPIs was observed at $6 \mathrm{~h}$ after administration. The gene expression of the lipoplex DPIs was significantly lower compared with that of the lipoplex/BSA DPIs at $6(p<0.01)$, $12(p<0.01)$, and $24 \mathrm{~h}(p<0.05)$. These variances may be caused by differences in the mean particle sizes of the DPI formulations. In general, large sized liposomes are taken up by macrophages. Chono et al. have reported that the uptake 
of liposomes by rat alveolar macrophages increased with an increase in particle size over the range of $100-1000 \mathrm{~nm}^{29}$ ) Since the size of lipoplex DPI was $1005 \pm 59.6 \mathrm{~nm}$ (Table 2), it is likely to be taken up by alveolar macrophages.

In conclusion, we examined the physicochemical properties and transfection characteristics of lipoplex/BSA DPIs. The results suggest that BSA is a useful lyoprotectant for preparations of DNA dry powder formulations by the spray-freeze drying method, given that only slight variations in physical properties and gene expression were observed.

Acknowledgement This work was supported by a Grantin-Aid for Scientific Research (A) from the Japan Society for the Promotion of Science (JSPS) (23240072).

\section{REFERENCES}

1) Ross G, Erickson R, Knorr D, Motulsky AG, Parkman R, Samulski J, Straus SE, Smith BR. Gene therapy in the United States: a fiveyear status report. Hum. Gene Ther., 7, 1781-1790 (1996).

2) Yang Y, Nunes FA, Berencsi K, Furth EE, Gönczöl E, Wilson JM. Cellular immunity to viral antigens limits E1-deleted adenoviruses for gene therapy. Proc. Natl. Acad. Sci. U.S.A., 91, 4407-4411 (1994).

3) Rogy MA, Beinhauer BG, Reinisch W, Huang L, Pokieser P. Transfer of interleukin-4 and interleukin-10 in patients with severe inflammatory bowel disease of the rectum. Hum. Gene Ther., 11, 1731-1741 (2000).

4) Nabel GJ, Nabel EG, Yang Z-Y, Fox BA, Plautz GE, Gao X, Huang L, Shu S, Gordon D, Chang AE. Direct gene transfer with DNAliposome complexes in melanoma: expression, biologic activity, and lack of toxicity in humans. Proc. Natl. Acad. Sci. U.S.A., 90, 11307-11311 (1993).

5) Rubin J, Galanis E, Pitot HC, Richardson RL, Burch PA, Charboneau JW, Reading CC, Lewis BD, Stahl S, Akporiaye ET, Harris DT. Phase I study of immunotherapy of hepatic metastases of colorectal carcinoma by direct gene transfer of an allogeneic histocompatibility antigen, HLA-B7. Gene Ther., 4, 419-425 (1997).

6) Kim HW, Park IK, Cho CS, Lee KH, Beck GR Jr, Colburn NH, Cho MH. Aerosol delivery of glucosylated polyethylenimine/phosphatase and tensin homologue deleted on chromosome 10 complex suppresses Akt downstream pathways in the lung of K-ras null mice. Cancer Res., 64, 7971-7976 (2004).

7) Davies LA, McLachlan G, Sumner-Jones SG, Ferguson D, Baker A, Tennant P, Gordon C, Vrettou C, Baker E, Zhu J, Alton EW, Collie DD, Porteous DJ, Hyde SC, Gill DR. Enhanced lung gene expression after aerosol delivery of concentrated pDNA/PEI complexes. Mol. Ther., 16, 1283-1290 (2008).

8) Chadwick SL, Kingston HD, Stern M, Cook RM, O'Connor BJ, Lukasson M, Balfour RP, Rosenberg M, Cheng SH, Smith AE, Meeker DP, Geddes DM, Alton EW. Safety of a single aerosol administration of escalating doses of the cationic lipid GL-67/DOPE/ DMPE-PEG5000 formulation to the lungs of normal volunteers. Gene Ther., 4, 937-942 (1997).

9) Adi H, Young PM, Chan HK, Stewart P, Agus H, Traini D. Cospray dried antibiotics for dry powder lung delivery. J. Pharm. Sci., 97, 3356-3366 (2008).

10) Okamoto H, Danjo K. Application of supercritical fluid to preparation of powders of high-molecular weight drugs for inhalation. $A d v$. Drug Deliv. Rev., 60, 433-446 (2008).

11) Byron PR. Some future perspectives for unit dose inhalation aerosols. Drug Dev. Ind. Pharm., 12, 993-1015 (1986).

12) Newman SP, Hollingworth A, Clark AR. Effect of different modes of inhalation on drug delivery from a dry powder inhaler. Int. J. Pharm., 102, 127-132 (1994).

13) Lu D, Hickey AJ. Liposomal dry powders as aerosols for pulmonary delivery of proteins. AAPS PharmSciTech, 6, E641-E648 (2005).

14) Pfeifer $C$, Hasenpusch $G$, Uezguen $S$, Aneja MK, Reinhardt D, Kirch J, Schneider M, Claus S, Friess W, Rudolph C. Dry powder aerosols of polyethylenimine (PEI)-based gene vectors mediate efficient gene delivery to the lung. J. Control. Release, 154, 69-76 (2011).

15) Takahashi H, Chen R, Okamoto H, Danjo K. Acetaminophen particle design using chitosan and a spray-drying technique. Chem. Pharm. Bull., 53, 37-41 (2005).

16) Gilani K, Rouholamini Najafabadi A, Barghi M, Rafiee-Tehrani M. Aerosolisation of beclomethasone dipropionate using spray dried lactose/polyethylene glycol carriers. Eur. J. Pharm. Biopharm., 58, 595-606 (2004).

17) Seville PC, Kellaway IW, Birchall JC. Preparation of dry powder dispersions for non-viral gene delivery by freeze-drying and spraydrying. J. Gene Med., 4, 428-437 (2002).

18) Kuo JH. The effect of protective agents on the stability of plasmid DNA by the process of spray-drying. J. Pharm. Pharmacol., 55, 301-306 (2003).

19) Kuo JH, Hwang R. Preparation of DNA dry powder for non-viral gene delivery by spray-freeze drying: effect of protective agents (polyethyleneimine and sugars) on the stability of DNA. J. Pharm. Pharmacol., 56, 27-33 (2004).

20) Mohri K, Okuda T, Mori A, Danjo K, Okamoto H. Optimized pulmonary gene transfection in mice by spray-freeze dried powder inhalation. J. Control. Release, 144, 221-226 (2010).

21) Ausborn M, Schreier H, Brezesinski G, Fabian H, Meyer HW, Nuhn P. The protective effect of free and membrane-bound cryoprotectants during freezing and freeze-drying of liposomes. J. Control. Release, 30, 105-116 (1994).

22) Yadava P, Gibbs M, Castro C, Hughes JA. Effect of lyophilization and freeze-thawing on the stability of siRNA-liposome complexes. AAPS PharmSciTech, 9, 335-341 (2008).

23) Maitani Y, Aso Y, Yamada A, Yoshioka S. Effect of sugars on storage stability of lyophilized liposome/DNA complexes with high transfection efficiency. Int. J. Pharm., 356, 69-75 (2008).

24) Kawakami $S$, Fumoto $S$, Nishikawa M, Yamashita F, Hashida M. In vivo gene delivery to the liver using novel galactosylated cationic liposomes. Pharm. Res., 17, 306-313 (2000).

25) Sakurai F, Nishioka T, Saito H, Baba T, Okuda A, Matsumoto O, Taga T, Yamashita F, Takakura Y, Hashida M. Interaction between DNA-cationic liposome complexes and erythrocytes is an important factor in systemic gene transfer via the intravenous route in mice: the role of the neutral helper lipid. Gene Ther., 8, 677-686 (2001).

26) Kawakami S, Sato A, Nishikawa M, Yamashita F, Hashida M. Mannose receptor-mediated gene transfer into macrophages using novel mannosylated cationic liposomes. Gene Ther., 7, 292-299 (2000).

27) Okamoto $\mathrm{H}$, Aoki M, Danjo K. A novel apparatus for rat in vivo evaluation of dry powder formulations for pulmonary administration. J. Pharm. Sci., 89, 1028-1035 (2000).

28) Mizuno T, Mohri K, Nasu S, Danjo K, Okamoto H. Dual imaging of pulmonary delivery and gene expression of dry powder inhalant by fluorescence and bioluminescence. J. Control. Release, 134, 149-154 (2009).

29) Chono S, Tanino T, Seki T, Morimoto K. Uptake characteristics of liposomes by rat alveolar macrophages: influence of particle size and surface mannose modification. J. Pharm. Pharmacol., 59, 75-80 (2007). 